\title{
Temperature Effects on the Whiskers in Rare-Earth Doped Sn-3Ag-0.5Cu-0.5Ce Solder Joints
}

\begin{abstract}
TUNG-HAN CHUANG
The whisker growth in $\mathrm{Sn}-3 \mathrm{Ag}-0.5 \mathrm{Cu}-0.5 \mathrm{Ce}$ solder joints after storage at various temperatures is investigated. After reflow, cluster-shaped $\mathrm{CeSn}_{3}$ precipitates form in the solder matrix. It is much easier for the surface of the $\mathrm{CeSn}_{3}$ phases to oxidize than for the solder matrix. The oxidation of the outer surface of these $\mathrm{CeSn}_{3}$ precipitates is accompanied by rapid growth of tin whiskers. Storage temperature affects the morphology and growth kinetics of the whiskers, which are also correlated with the oxidation rates of the $\mathrm{CeSn}_{3}$ surface at various temperatures. The results showed that the driving force for the growth of tin whiskers in this $\mathrm{Sn}-3 \mathrm{Ag}-0.5 \mathrm{Cu}-$ $0.5 \mathrm{Ce}$ solder is the compressive stress induced by the diffusion of oxygen into the $\mathrm{CeSn}_{3}$ precipitate clusters, which results in the lattice expansion in the oxidized $\mathrm{CeSn}_{3}$ phase.
\end{abstract}

DOI: $10.1007 / \mathrm{s} 11661-007-9126-5$

(C) The Minerals, Metals \& Materials Society and ASM International 2007

\section{INTRODUCTION}

DUE to the chemical activity of rare-earth (RE) elements, they have been effectively applied for the refining of casting microstructure ${ }^{[1,2]}$ or the bonding of nonwettable materials. ${ }^{[3,4,5]}$ Recently, RE elements have been added into solder alloys to improve their physical and mechanical properties. Ma et al. added $0.05 \mathrm{wt}$ pet $\mathrm{La}$ to a $\mathrm{Sn}-40 \mathrm{~Pb}$ solder and observed that the intermetallic compounds at the interfaces of solder joints were

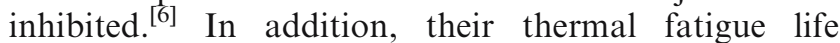
increased by a factor of 3 . Chen et al. found that the addition of $0.2 \mathrm{wt}$ pet mixed metal $(\mathrm{Ce}, \mathrm{La})$ to a $\mathrm{Sn}-3.8 \mathrm{Ag}-0.7 \mathrm{Cu}$ solder caused the refining of its microstructure and the formation of needlelike $\mathrm{Ag}_{3} \mathrm{Sn}$ precipitates, through which the creep rupture life rose seven folds. ${ }^{[7]}$ Dudek et al. added $0.5 \mathrm{wt}$ pct La into a Sn-3.9Ag- $0.7 \mathrm{Cu}$ solder and showed that the strain to failure of samples increased nearly 150 pct over that of the undoped alloy. ${ }^{[8]} \mathrm{Wu}$ et al. also reported that a Sn-3.5Ag solder containing 0.25 wt pet mixed metal possessed better wettability, tensile strength, and creep resistance than undoped alloys. ${ }^{[9]}$ For the $\mathrm{Sn}-0.7 \mathrm{Cu}$ solder, Wu et al. further indicated that alloying with $0.5 \mathrm{wt}$ pct mixed metal could refine its grain size and provide a fine and uniform distribution of $\mathrm{Cu}_{6} \mathrm{Sn}_{5}$ intermetallic compounds in the solidified matrix, which resulted in significant improvements of its tensile strength, microhardness, and creep resistance. Upon aging at $150^{\circ} \mathrm{C}$ for 20 hours, the microstructure of such a $\mathrm{Sn}-0.7 \mathrm{Cu}-\mathrm{RE}$ solder is more stable than that of the undoped $\mathrm{Sn}-0.7 \mathrm{Cu}$ alloy. ${ }^{[10]}$ The beneficial effects of RE addition have also been shown to be effective for Sn-9Zn solder. Wu et al. reported that the Sn-9Zn-RE solder

TUNG-HAN CHUANG, Professor, is with the Institute of Materials Science and Engineering, National Taiwan University, Taipei 106,

Taiwan, R.O.C. Contact e-mail: tunghan@ntu.edu.tw

Manuscript submitted July 12, 2006.

Article published online April 21, 2007. exhibited finer $\beta$-Sn grains and higher tensile strength than the undoped Sn-9Zn alloy. ${ }^{[1]}$ In addition, the wetting properties of Sn-9Zn-RE solder were greatly improved due to the decrease of surface tension. Summarizing these experimental results, $\mathrm{Wu}$ et al. concluded in a review article that RE elements would play an important role in providing better electronic interconnections. ${ }^{[12]}$

However, an amazingly rapid growth of tin whiskers has been observed in a $\mathrm{Sn}-3 \mathrm{Ag}-0.5 \mathrm{Cu}-0.5 \mathrm{Ce}$ solder joint after room temperature storage in air for just a few days. ${ }^{[13]}$ Because the appearance of tin whiskers in solder joints will cause short circuits, the addition of RE elements to solder alloys could be risky for electronic devices in actual application. Furthermore, during the operation of electronic devices, the temperature of solder joints is increased. The morphology and growth kinetics of tin whiskers might be affected by the storage temperature. The focus of this study has thus been the temperature effects on the whisker growth in this $\mathrm{RE}$ element containing $\mathrm{Sn}-3 \mathrm{Ag}-0.5 \mathrm{Cu}-0.5 \mathrm{Ce}$ solder.

\section{EXPERIMENTAL}

The $\mathrm{Sn}-3 \mathrm{Ag}-0.5 \mathrm{Cu}-0.5 \mathrm{Ce}$ solder used for this study was prepared by melting a Sn-6.6 wt pct Ce master alloy at $1000{ }^{\circ} \mathrm{C}$ under $10^{-4} \mathrm{~Pa}$ vacuum and then remelting it with the addition of the elements $\mathrm{Sn}, \mathrm{Ag}$, and $\mathrm{Cu}$ under the same conditions. The ingot was rolled into a 180 $\mu \mathrm{m}$-thick plate and punched into a disk of $400 \mu \mathrm{m}$ in diameter. The solder disks, after being dipped in rosin mildly activated flux, were placed on the Ag surfacefinished $\mathrm{Cu}$ pads of a ball grid array package. The specimens were then reflowed in a hot-air furnace using a temperature profile with the soaking temperature and peak temperature at $150{ }^{\circ} \mathrm{C}$ and $240{ }^{\circ} \mathrm{C}$, respectively. The surface tension of the molten solder caused the solder disks to become solder balls after solidification. The reflowed specimens were cut from cross sections of a 
row of solder balls, ground with 2000 grit $\mathrm{SiC}$ paper, and polished with $0.3-\mu \mathrm{m} \mathrm{Al}_{2} \mathrm{O}_{3}$ powder. Some of the cross-sectioned solder joints were further aged for various storage durations at room temperature and at $50{ }^{\circ} \mathrm{C}, 100{ }^{\circ} \mathrm{C}$, and $150{ }^{\circ} \mathrm{C}$ in an air furnace. Both the reflowed and aged specimens were observed via scanning electron microscopy, and their chemical compositions were analyzed using an electron probe microanalyzer (EPMA).

\section{RESULTS AND DISCUSSION}

After reflow, large-sized intermetallic clusters with a composition of $\mathrm{CeSn}_{3}$ form in the solder matrix, as shown in Figure 1(a). Figure 1(b) reveals that after 3 days of further storage at room temperature in air, many thread-shaped whiskers appear in the region of the $\mathrm{CeSn}_{3}$ precipitates. The lengths of some whiskers are
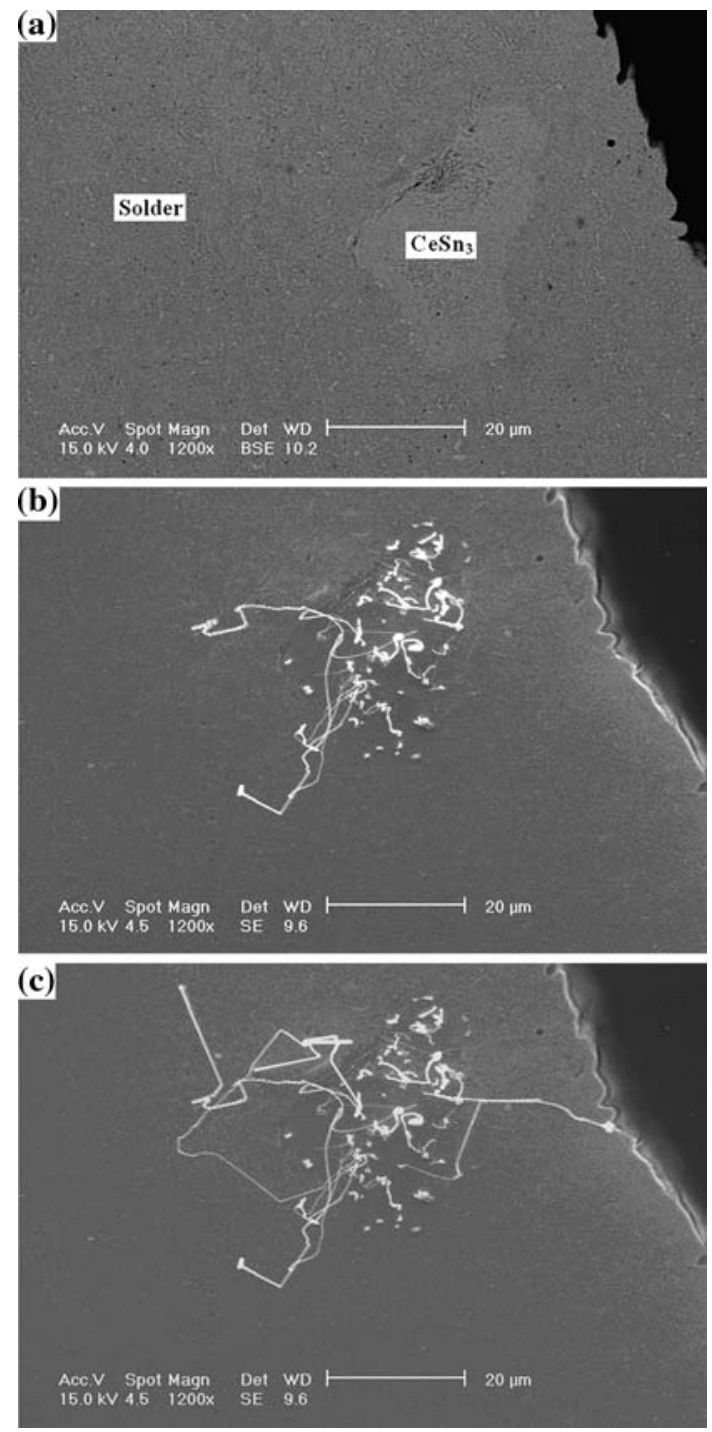

Fig. $1-$ Whisker growth in a $\mathrm{Sn}-3 \mathrm{Ag}-0.5 \mathrm{Cu}-0.5 \mathrm{Ce}$ solder joint after air storage at room temperature for various times: (a) as-reflowed, (b) 3 days, and (c) 10 days. over $30 \mu \mathrm{m}$, and their diameters are about 0.1 to $0.3 \mu \mathrm{m}$. The whiskers grow very quickly after room-temperature storage for longer time durations (Figure 1(c)). However, the diameters remain unchanged during the growth of the whiskers. The EPMA analyses show that the chemical compositions of these threadlike whiskers are near pure tin, with small amounts of oxygen. Figure 2 shows that in the case of air storage at $50{ }^{\circ} \mathrm{C}$, the whiskers in $\mathrm{Sn}-3 \mathrm{Ag}-0.5 \mathrm{Cu}-0.5 \mathrm{Ce}$ solder joints have a morphology similar to that observed for the specimens aged at room temperature. However, some hillockshape whiskers can be found at the edges of the $\mathrm{CeSn}_{3}$ precipitates. The size of these hillocks is about $5 \mu \mathrm{m}$, with the length much shorter than that of the threadshaped whiskers.

When the aging temperature is increased to $100{ }^{\circ} \mathrm{C}$, the hillock-type whiskers become dominant, as shown in Figure 3. However, a small number of thread-type whiskers can still be observed. These fine whiskers can
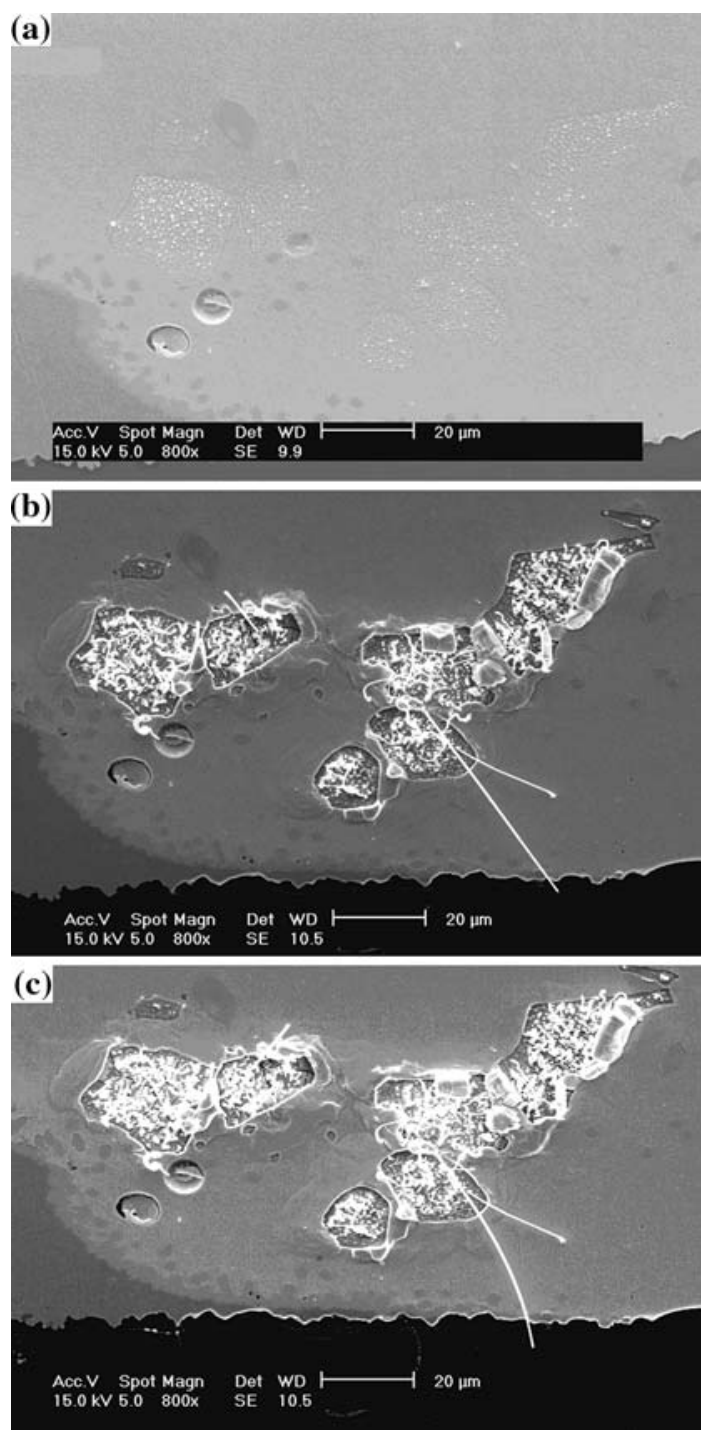

Fig. 2-Whisker growth in a $\mathrm{Sn}-3 \mathrm{Ag}-0.5 \mathrm{Cu}-0.5 \mathrm{Ce}$ solder joint after air storage at $50{ }^{\circ} \mathrm{C}$ for various times: $(a)$ as-reflowed, (b) 2 days, and (c) 21 days. 

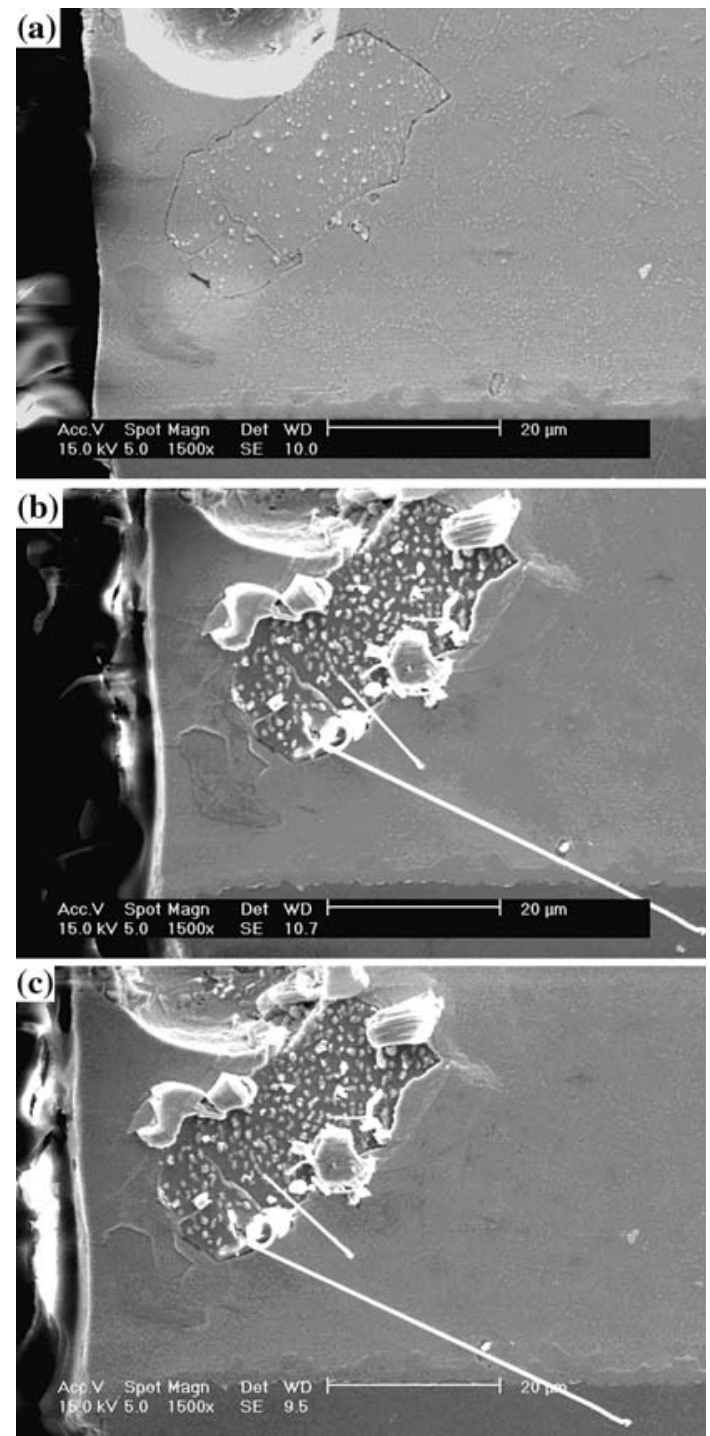

Fig. 3-Whisker growth in a $\mathrm{Sn}-3 \mathrm{Ag}-0.5 \mathrm{Cu}-0.5 \mathrm{Ce}$ solder joint after air storage at $100{ }^{\circ} \mathrm{C}$ for various times: (a) as-reflowed, (b) 2 days, and (c) 21 days.

nevertheless grow quickly to a length of over $40 \mu \mathrm{m}$ in just 2 days, as indicated in Figure 3(b). When the storage temperature is raised further to $150{ }^{\circ} \mathrm{C}$, thread-type whiskers can scarcely be found in the specimens. In contrast, the edges of the $\mathrm{CeSn}_{3}$ phase are full of hillock-type whiskers, as revealed by Figure 4. Figure 4 also shows that these hillocks appear in as short a time as 0.25 hours. However, both the diameter and length of these hillock-type whiskers cease to increase when the specimens are further stored in air for longer periods. The occurrence percentages of hillock-type whiskers and the average whisker lengths in $\mathrm{Sn}-3 \mathrm{Ag}-0.5 \mathrm{Cu}-0.5 \mathrm{Ce}$ solder joints are plotted in dependence of the storage temperatures (Figure 5). It can be seen that, along with the rise of storage temperature, the occurrence percentage of hillock-type whiskers increases from 20 to $86 \mathrm{pct}$, and the average length of the whiskers decreases from 52.6 to $18.6 \mu \mathrm{m}$.
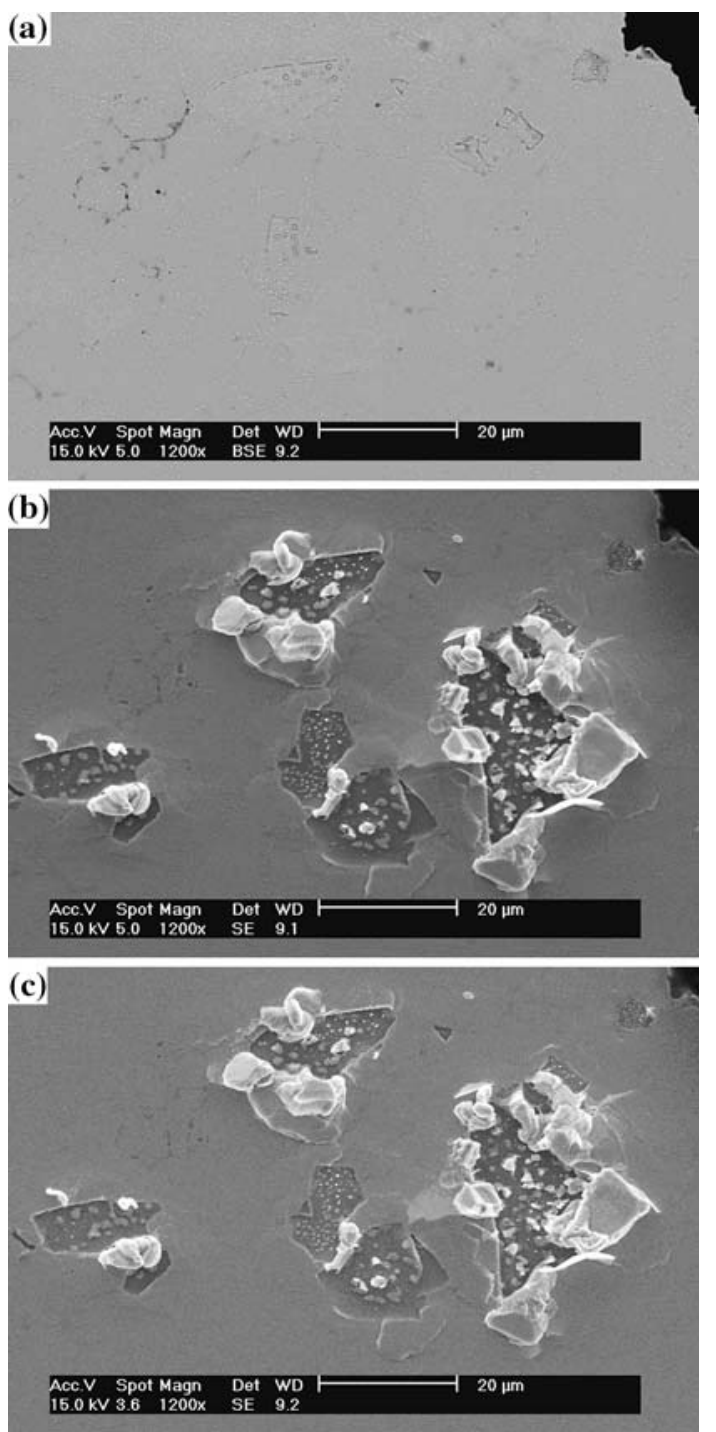

Fig. 4 -Hillock-type whisker growth in a $\mathrm{Sn}-3 \mathrm{Ag}-0.5 \mathrm{Cu}-0.5 \mathrm{Ce}$ solder joint after air storage at $150{ }^{\circ} \mathrm{C}$ for short periods: $(a)$ as-reflowed, $(b)$ $0.25 \mathrm{~h}$, and $(c) 0.5 \mathrm{~h}$.

In comparison to the morphology of $\mathrm{CeSn}_{3}$ phases observed in the $\mathrm{Sn}-3 \mathrm{Ag}-0.5 \mathrm{Cu}-0.5 \mathrm{Ce}$ solder joints after air storage, tin whiskers are absent when specimens have been aged at room temperature under $10^{-2} \mathrm{~Pa}$ vacuum for various time periods up to 21 days, as illustrated in Figure 6. A similar result has also been obtained in the case of $150{ }^{\circ} \mathrm{C}$ storage in a vacuum furnace of $10^{-2} \mathrm{~Pa}$ for 3 hours.

It is interesting that EPMA analyses indicate that the hillocks at the edge of the $\mathrm{CeSn}_{3}$ phase contain a certain amount of $\mathrm{Ag}$, which is quite different from the chemical composition of the thread-type whiskers. In a few cases, $\mathrm{Ag}_{3} \mathrm{Sn}$ particles are even found to be embedded in the surface of the hillocks, which results in the Ag content in the hillocks reaching an amount of 24 at. pct. This result implies that the surrounding hillocks have sprouted from the $\mathrm{Sn}-3 \mathrm{Ag}-0.5 \mathrm{Cu}-0.5 \mathrm{Ce}$ solder matrix, rather than from the $\mathrm{CeSn}_{3}$ precipitates. 


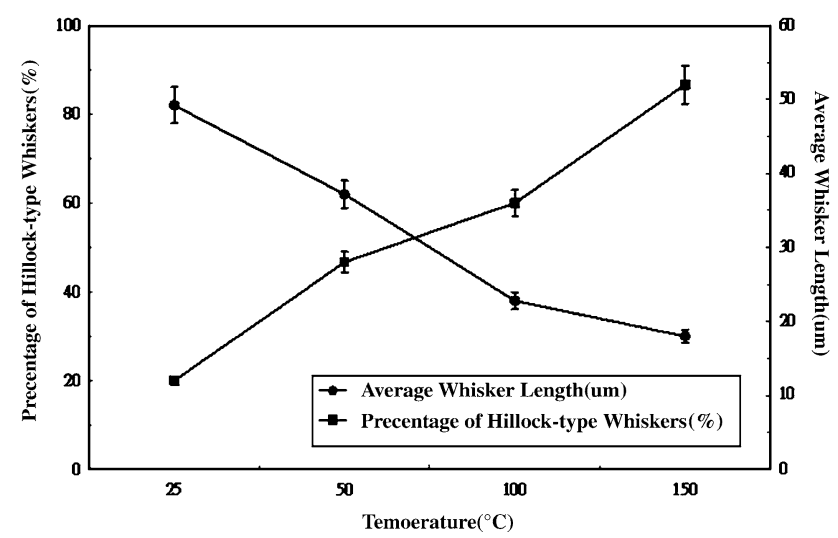

Fig. 5-Occurrence percentage of hillock-type whiskers and their average length for $\mathrm{Sn}-3 \mathrm{Ag}-0.5 \mathrm{Cu}-0.5 \mathrm{Ce}$ solder joints after storage at various temperatures.
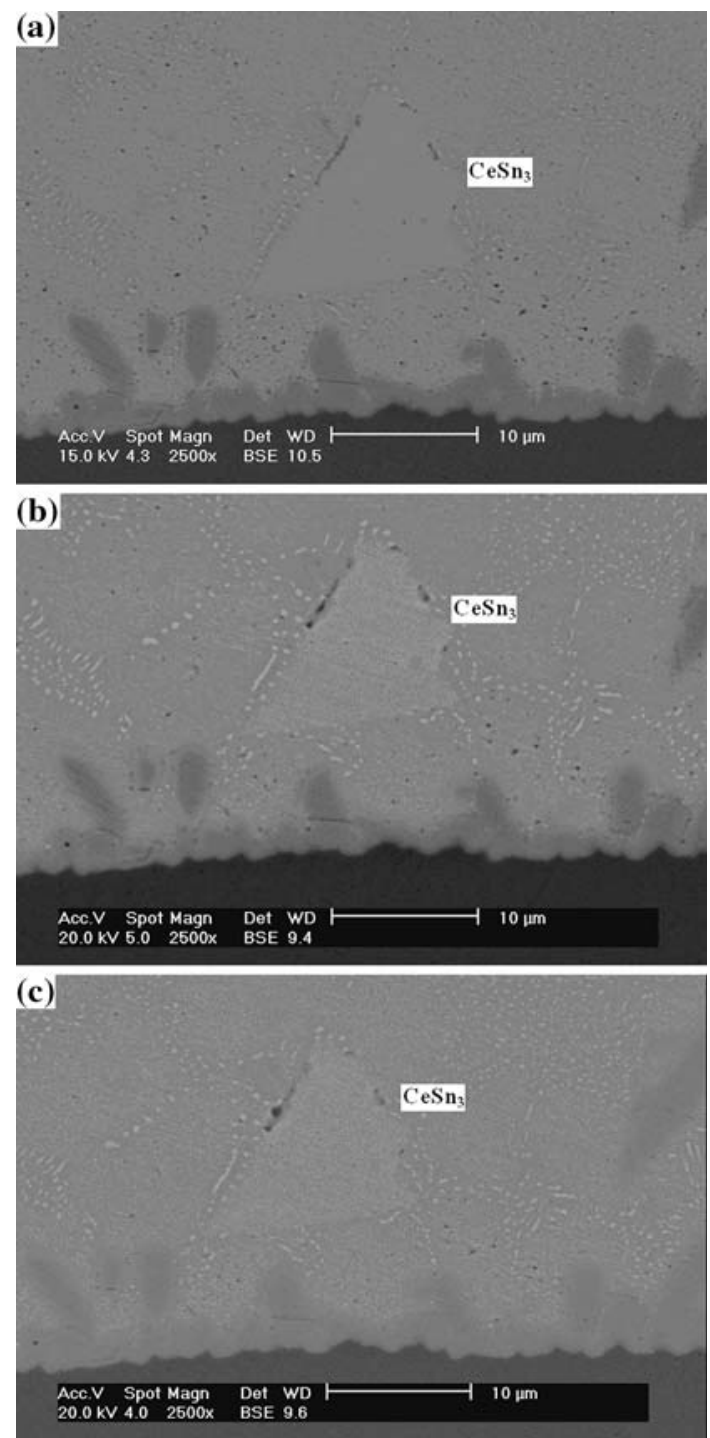

Fig. 6-Morphology of $\mathrm{CeSn}_{3}$ precipitates in $\mathrm{Sn}-3 \mathrm{Ag}-0.5 \mathrm{Cu}-0.5 \mathrm{Ce}$ solder joints after storage at room temperature under $10^{-2} \mathrm{~Pa}$ vacuum for various times: $(a)$ as reflowed, $(b) 10$ days, and (c) 21 days.
Liu et al. studied whisker growth along with the electromigration in Sn thin films, observing that both needle-shaped and hillock-type whiskers grow at the anode when the films are stressed at room temperature and at $50{ }^{\circ} \mathrm{C}$. However, only hillock-type whiskers have been observed when the films are stressed at $75^{\circ} \mathrm{C}$ and $100{ }^{\circ} \mathrm{C}$. They suggested that the result may be attributed to the softer surface oxide formed at higher temperatures. ${ }^{[14]} \mathrm{Tu}$ also reported on the dominant formation of hillock-type whiskers at higher temperatures. ${ }^{[15]}$ To model the hillock growth, he assumed that whiskers grow at weaker spots on the Sn surface where the surface oxide has been broken, and these spots become localized stress relief centers surrounded by a long-range stress gradient needed for whisker growth.

In order to clarify the temperature effects on the morphology and growth kinetics of tin whiskers in this study, the chemical compositions of the oxide layers on $\mathrm{CeSn}_{3}$ phases after the storage of specimens at various temperatures have been analyzed. Figure 7 reveals that the surface of $\mathrm{CeSn}_{3}$ intermetallic clusters in the asreflowed $\mathrm{Sn}-3 \mathrm{Ag}-0.5 \mathrm{Cu}-0.5 \mathrm{Ce}$ solder joints contains only a slight amount of oxygen. However, the oxygen content on the surface of the $\mathrm{CeSn}_{3}$ phase rises to about 50 at. pet after air storage for 15 days and then remains almost constant with further increases in aging time at room temperature. Along with the rise of the oxygen content, the Ce content also increases slightly, accompanied by the plummeting of the Sn content. The composition (at. pet) of the surface of the $\mathrm{CeSn}_{3}$ intermetallic phase after long-term storage at room temperature is $\mathrm{Ce}: \mathrm{Sn}: \mathrm{O}=40.0: 7.5: 52.5$. The oxygen content on the surface of the $\mathrm{CeSn}_{3}$ phase rises to its maximum value (49 at. pct) after air storage at $50{ }^{\circ} \mathrm{C}$ for 3 days, as shown in Figure 8. The final composition after long-term storage at $50{ }^{\circ} \mathrm{C}$ is $\mathrm{Ce}: \mathrm{Sn}: \mathrm{O}=$ 45.0:7.0:48.0. When the storage temperature is raised further to $100{ }^{\circ} \mathrm{C}$ and $150{ }^{\circ} \mathrm{C}$, the time durations needed for the oxygen content on $\mathrm{CeSn}_{3}$ surfaces to attain its

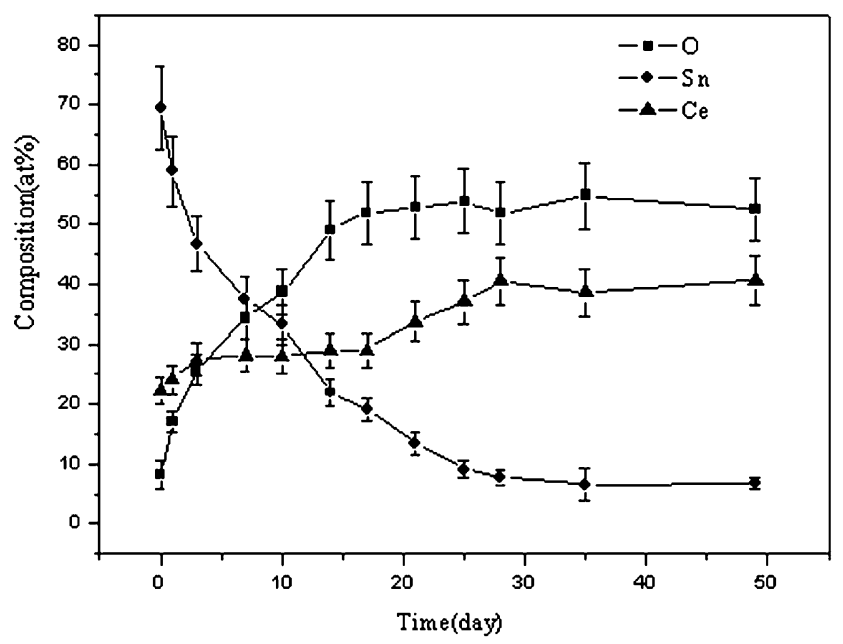

Fig. 7-Composition profile of the surface of $\mathrm{CeSn}_{3}$ intermetallic clusters formed in $\mathrm{Sn}-3 \mathrm{Ag}-0.5 \mathrm{Cu}-0.5 \mathrm{Ce}$ specimens stored at room temperature in air for various times. 


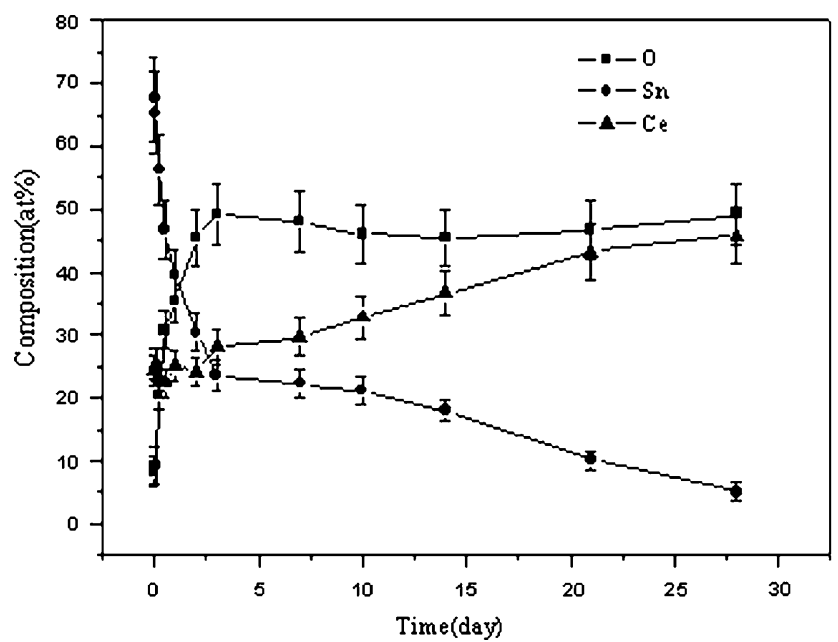

Fig. 8 - Composition profile of the surface of $\mathrm{CeSn}_{3}$ intermetallic clusters formed in $\mathrm{Sn}-3 \mathrm{Ag}-0.5 \mathrm{Cu}-0.5 \mathrm{Ce}$ specimens stored at $50{ }^{\circ} \mathrm{C}$ in air furnace for various times.

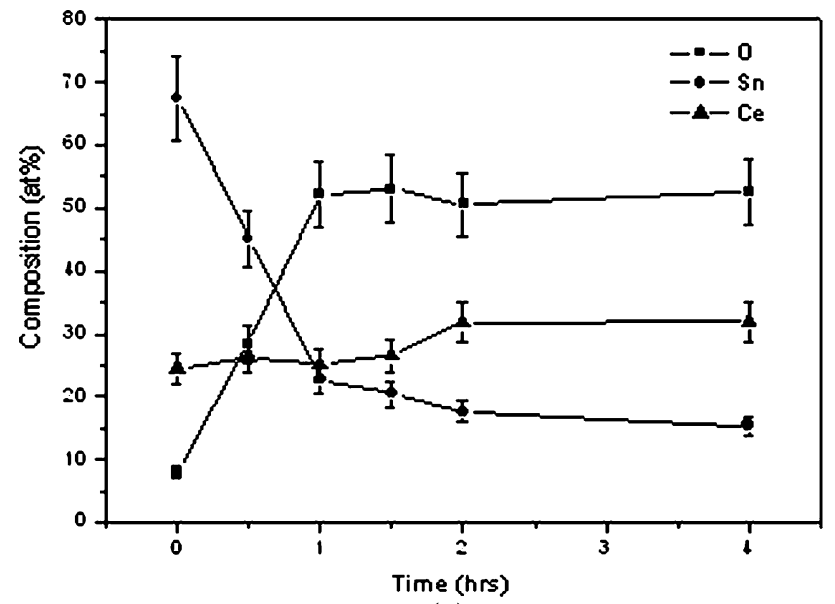

(a)

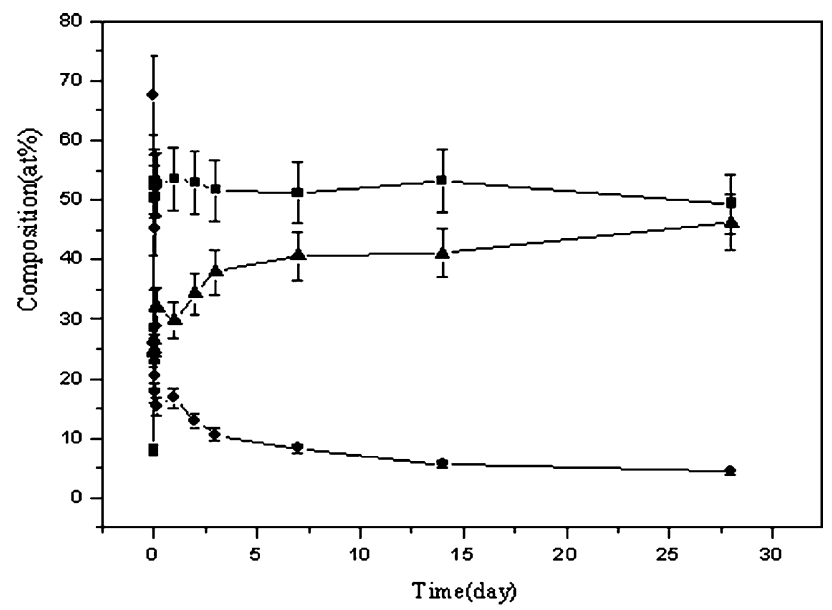

(b)

Fig. 9- Composition profile of the surface of $\mathrm{CeSn}_{3}$ intermetallic clusters formed in $\mathrm{Sn}-3 \mathrm{Ag}-0.5 \mathrm{Cu}-0.5 \mathrm{Ce}$ specimens stored at $100{ }^{\circ} \mathrm{C}$ in air furnace for various times: $(a)$ shorter-term storage and $(b)$ longer-term storage. maximum value are 1 and 0.5 hours, respectively, as indicated by Figures 9 and 10. The final compositions of oxide on $\mathrm{CeSn}_{3}$ surfaces after long-term storage at $100{ }^{\circ} \mathrm{C}$ and $150{ }^{\circ} \mathrm{C}$ are $\mathrm{Ce}_{46.0} \mathrm{Sn}_{4.0} \mathrm{O}_{50.0}$ and $\mathrm{Ce}_{45.0} \mathrm{~S}$ $\mathrm{n}_{4.5} \mathrm{O}_{50.5}$, respectively. Collating the observations of whisker growth with the surface composition analyses of the $\mathrm{CeSn}_{3}$ phase, it is observed that the tin whiskers have stopped sprouting before the attainment of the maximum oxygen content.

Because EPMA analysis gives a maximum depth resolution of about $1 \mu \mathrm{m}$, the time duration needed for attaining the maximum oxygen content (Figures 7 to 10) represents the time that the oxide layer takes to grow to a thickness of about $1 \mu \mathrm{m}$. The reciprocal square root of time duration $\left(t^{-1 / 2}\right)$ for attaining the maximum oxygen content is plotted in an Arrhenius diagram $\left(\log t^{-1 / 2} v S\right.$ $1 / T$ ), as shown in Figure 11, which indicates an activation energy of $12.9 \mathrm{~kJ} / \mathrm{mol}$. This value is quite consistent with the activation energy $(15.1 \mathrm{~kJ} / \mathrm{mol})$ for the lattice diffusivity of trace radioactive $\mathrm{O}^{18}$ in cerium oxide, as measured by Steele and Floyd. ${ }^{[16]}$ It indicates that the

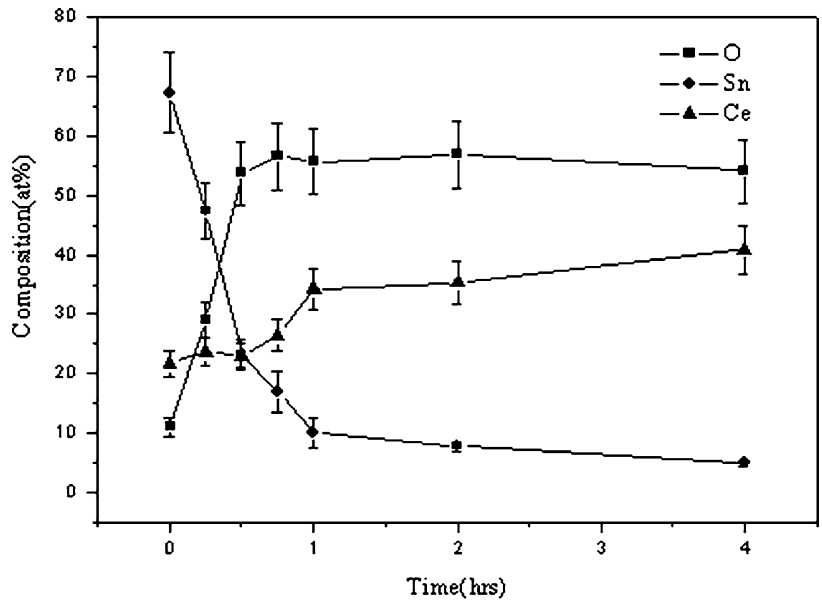

(a)

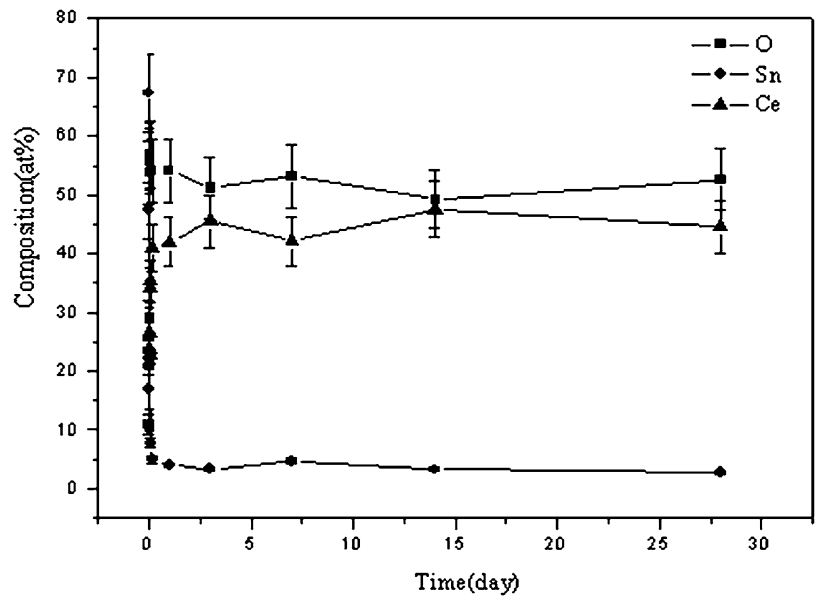

(b)

Fig. 10-Composition profile of the surface of $\mathrm{CeSn}_{3}$ intermetallic clusters formed in $\mathrm{Sn}-3 \mathrm{Ag}-0.5 \mathrm{Cu}-0.5 \mathrm{Ce}$ specimens stored at $150{ }^{\circ} \mathrm{C}$ in air furnace for various times: $(a)$ shorter-term storage and $(b)$ longer-term storage. 
growth kinetics of the oxide layer on the $\mathrm{CeSn}_{3}$ phase are controlled by the lattice diffusion of oxygen through the cerium oxide. The results confirm that the growth of tin whiskers in $\mathrm{Sn}-3 \mathrm{Ag}-0.5 \mathrm{Cu}-0.5 \mathrm{Ce}$ solder joints has a close relationship with the diffusion of oxygen into $\mathrm{CeSn}_{3}$ precipitates during the storage of the packages. In contrast to the composition profiles of the surfaces of $\mathrm{CeSn}_{3}$ intermetallic clusters in air-stored $\mathrm{Sn}-3 \mathrm{Ag}-0.5 \mathrm{Cu}-$ $0.5 \mathrm{Ce}$ solder joints, the contents of cerium, tin, and oxygen on the $\mathrm{CeSn}_{3}$ of specimens aged at room temperature under $10^{-2} \mathrm{~Pa}$ vacuum remain almost constant, as evidenced in Figure 12.

In order to further clarify the whisker growth mechanism in the $\mathrm{Sn}-3 \mathrm{Ag}-0.5 \mathrm{Cu}-0.5 \mathrm{Ce}$ solder joints, specimens were cut across the $\mathrm{CeSn}_{3}$ phase, as shown in Figures 13 and 14. The cross section of a specimen stored at room temperature for 21 days reveals an oxide layer of about $1 \mu \mathrm{m}$ in thickness on the $\mathrm{CeSn}_{3}$ phase (Figure 13(b)). On the other hand, Figure 14(b) shows a very thick oxide layer on the outer surface of the $\mathrm{CeSn}_{3}$ phase after storage at $150{ }^{\circ} \mathrm{C}$ for 3 hours. Surrounding the remaining unoxidized $\mathrm{CeSn}_{3}$ phase, a thinner oxide layer can also be observed. Through the morphological changes of $\mathrm{CeSn}_{3}$ phase and oxide layer in both cases, the mechanism for the formation of fiber-shaped whiskers and coarse hillocks in $\mathrm{Sn}-3 \mathrm{Ag}-0.5 \mathrm{Cu}-0.5 \mathrm{Ce}$ solder joints during the storage at room temperature and at elevated temperatures, respectively, can be schematically interpreted, as shown in Figures 15 and 16. Because the $\mathrm{RE}$ element $\mathrm{Ce}$ possesses high chemical activity, the $\mathrm{CeSn}_{3}$ precipitates react predominantly with oxygen and release the tin atoms: $2 \mathrm{CeSn}_{3}+\mathrm{O}_{2} \rightarrow 2 \mathrm{CeO}+6 \mathrm{Sn}$. The diffusion of oxygen into the $\mathrm{CeSn}_{3}$ phase leads to the expansion of its crystal lattice. This lattice expansion is constrained by the $\mathrm{CeSn}_{3}$ phase beneath the outer oxide layer, and the surrounding solder matrix, which introduces a compressive stress, causes the released tin atoms in $\mathrm{CeSn}_{3}$ precipitates to sprout out of the cerium oxide. At lower temperatures, the oxide on the surface

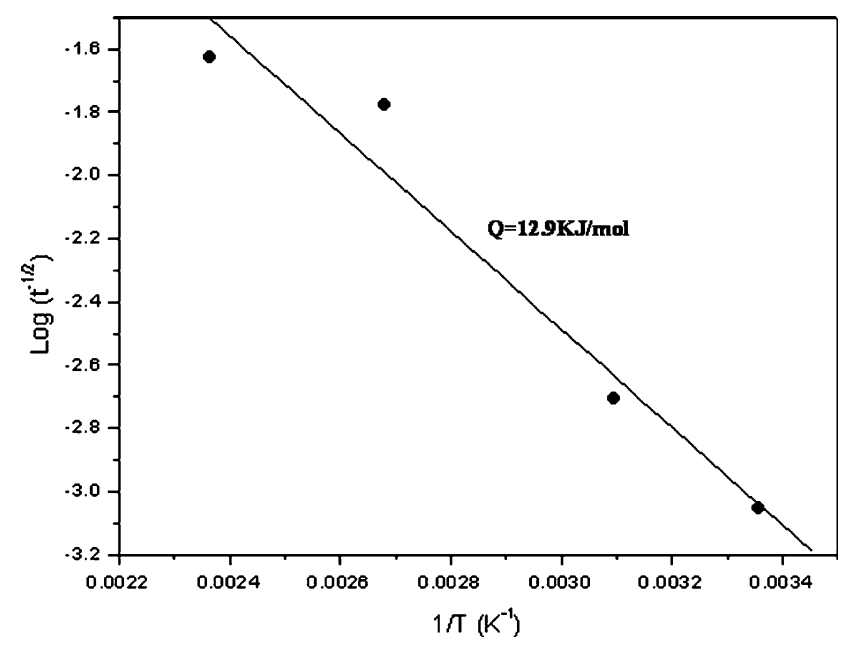

Fig. 11-Arrhenius plot of the reciprocal square root of time duration $\left(t^{-1 / 2}\right)$ for the oxygen content on the surface of $\mathrm{CeSn}_{3}$ phases in $\mathrm{Sn}-3 \mathrm{Ag}-0.5 \mathrm{Cu}-0.5 \mathrm{Ce}$ specimens after air storage to attain the maximal value.

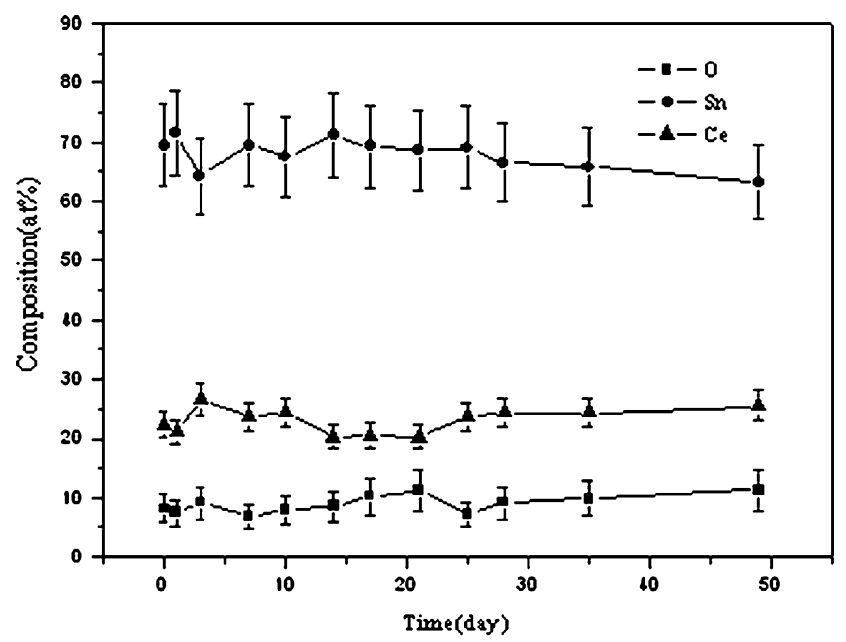

Fig. 12-Composition profile of the surface of $\mathrm{CeSn}_{3}$ intermetallic clusters formed in $\mathrm{Sn}-3 \mathrm{Ag}-0.5 \mathrm{Cu}-0.5 \mathrm{Ce}$ specimens stored at room temperature under $10^{-2} \mathrm{~Pa}$ vacuum for various times.
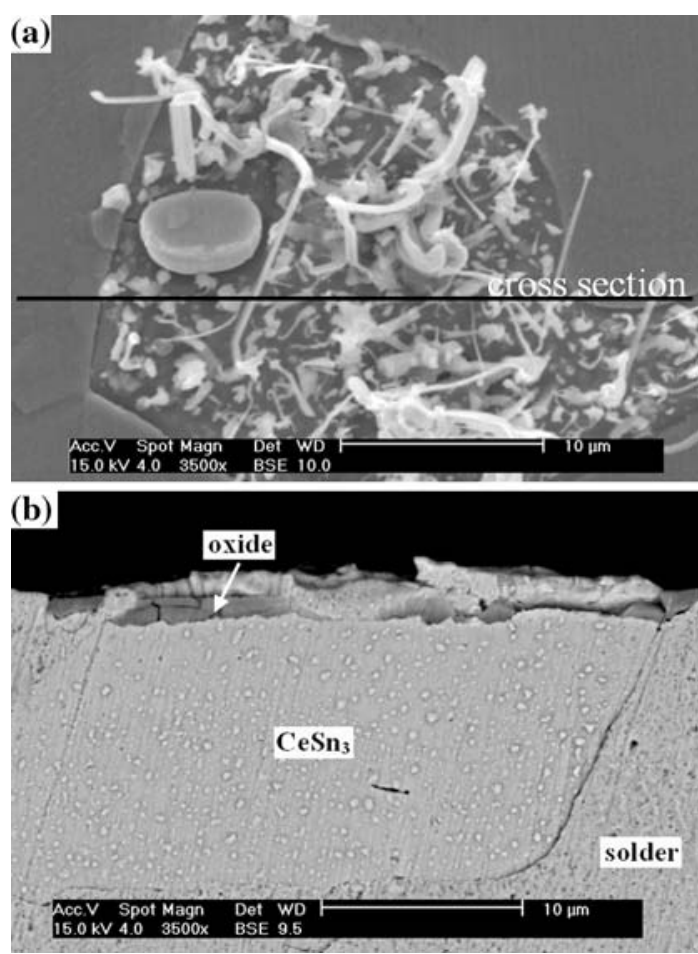

Fig. 13 - Cross section of an oxidized $\mathrm{CeSn}_{3}$ phase with whiskers that grew on its surface oxide for a $\mathrm{Sn}-3 \mathrm{Ag}-0.5 \mathrm{Cu}-0.5 \mathrm{Ce}$ solder joint after storage at room temperature for 10 days.

of $\mathrm{CeSn}_{3}$ phases grows more slowly. In this case, the resulting compressive stress increases slightly, and the released tin atoms are moderately transported through a number of weak spots within the oxide layer (Figure $15(\mathrm{~b}))$. The whiskers tend to be thin in diameter and grow continuously, even to a length of over $300 \mu \mathrm{m}$ (Figure 15(c)). In contrast, the high diffusion rate of oxygen through the cerium oxide during high-temperature storage causes the oxide layer on the $\mathrm{CeSn}_{3}$ phase to 

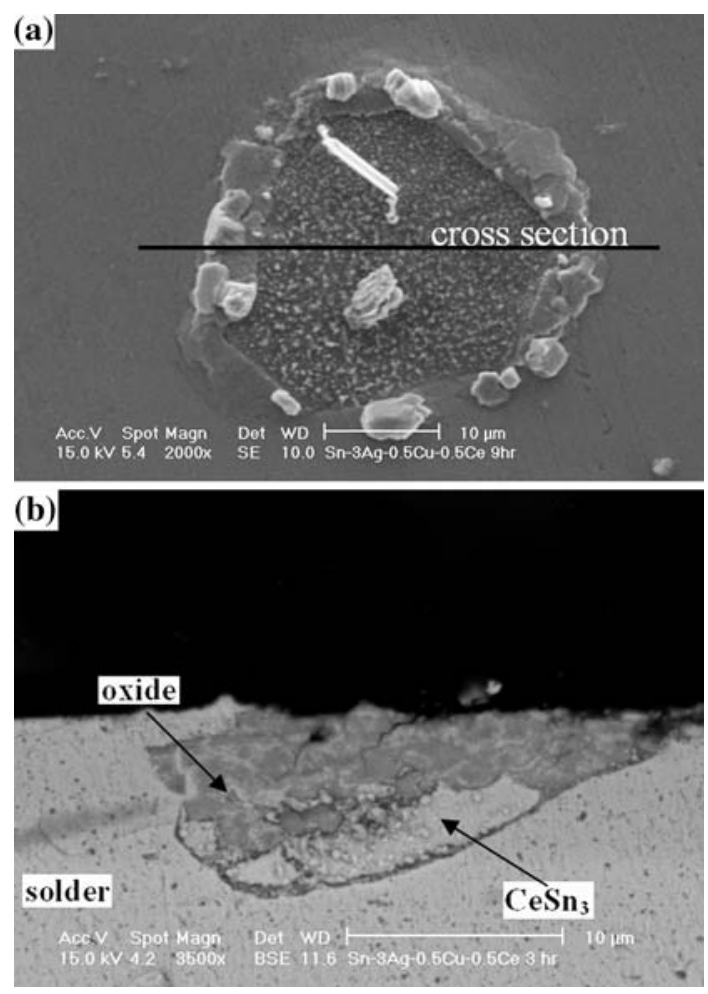

Fig. 14 Cross section of an oxidized $\mathrm{CeSn}_{3}$ phase with hillocks that grew around its oxide for a $\mathrm{Sn}-3 \mathrm{Ag}-0.5 \mathrm{Cu}-0.5 \mathrm{Ce}$ solder joint after storage at $150{ }^{\circ} \mathrm{C}$ for $3 \mathrm{~h}$.

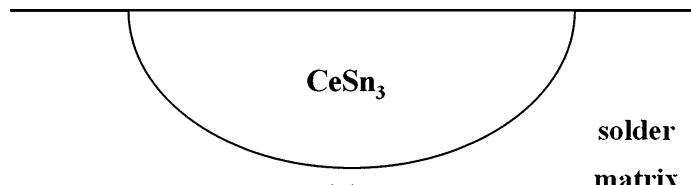

(a)

mativix

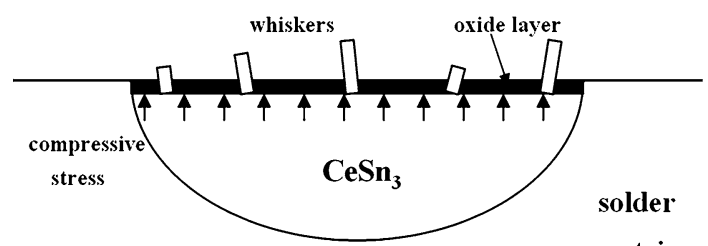

(b)

matrix

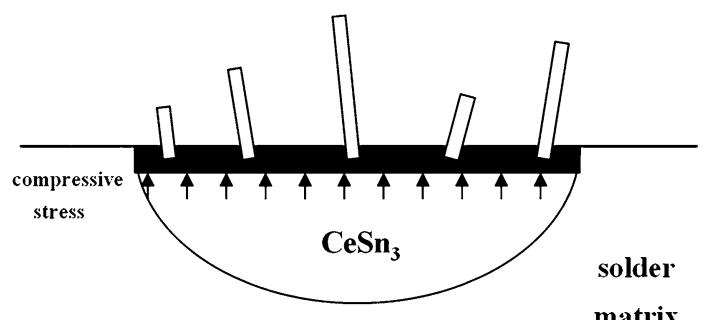

(c)

matrix

Fig. 15-Schematic representation of the mechanism for the formation of long fiber-shape whiskers during low-temperature storage of $\mathrm{Sn}-3 \mathrm{Ag}-0.5 \mathrm{Cu}-0.5 \mathrm{Ce}$ solder joints.

grow quickly to a sufficient thickness, without weak spots. The lattice expansion results in a compressive stress outward from the oxide layer, as shown in

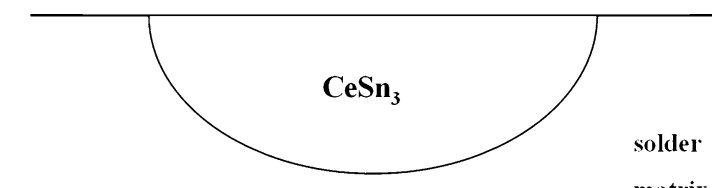

(a)

matrix

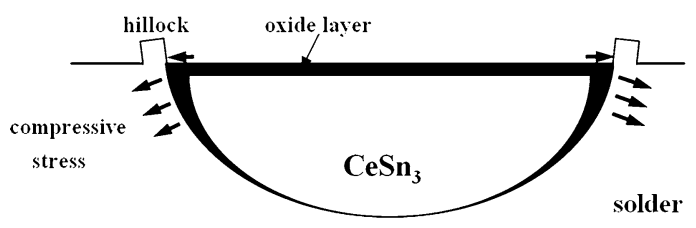

(b)

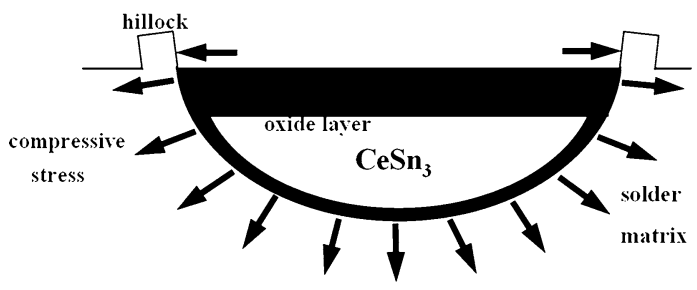

(c)

Fig. 16-Schematic representation of the mechanism for the formation of short hillock-shape whiskers during high-temperature storage of $\mathrm{Sn}-3 \mathrm{Ag}-0.5 \mathrm{Cu}-0.5 \mathrm{Ce}$ solder joints.

Figure 16(b). In addition, the oxygen can easily penetrate through the interface between the $\mathrm{CeSn}_{3}$ and solder matrix and react with the $\mathrm{CeSn}_{3}$ precipitates to form an oxide layer around the $\mathrm{CeSn}_{3}$ phase (Figure 16(c)). The lattice expansion caused by the oxygen invasion also induces a compressive stress on the surrounding solder matrix. Both compressive stresses cause the solder alloy around the $\mathrm{CeSn}_{3}$ phase to sprout out of the boundary between the $\mathrm{CeSn}_{3}$ cluster and solder matrix (Figure 16(c)). The resulting whiskers grow in coarse hillock forms and have a short length. The Ag content, as analyzed by EPMA in the surrounding hillocks, supports this interpretation.

\section{CONCLUSIONS}

In spite of the many advantages reported for solders doped with RE elements, abnormally rapid growth of tin whiskers can occur during storage in air. This growth is attributed to the predominate oxidation of $\mathrm{CeSn}_{3}$ precipitates, which releases the tin atoms. In this study, it is much easier for the surface of the $\mathrm{CeSn}_{3}$ precipitated clusters in a $\mathrm{Sn}-3 \mathrm{Ag}-0.5 \mathrm{Cu}-0.5 \mathrm{Ce}$ solder BGA package to oxidize than for the solder matrix. During the diffusion of oxygen into $\mathrm{CeSn}_{3}$ phases, the resulting compressive stress causes the released tin atoms to sprout from the weak spots of oxide layer on the $\mathrm{CeSn}_{3}$ surface. Diverse oxidation rates of the $\mathrm{CeSn}_{3}$ phase at various storage temperatures lead to a diversity of tin whisker morphologies. At lower temperatures, the surface of the $\mathrm{CeSn}_{3}$ precipitates oxidizes more slowly, which causes only a mild increase of the compressive stress. In this case, tin atoms are transported through 
many weak spots in the oxide layer, resulting in the formation of long and thin thread-type whiskers. However, the rapid diffusion of oxygen during hightemperature storage induces a compressive stress outward from the oxide layer of the $\mathrm{CeSn}_{3}$ phase. In addition, the diffusion of oxygen through the interface between the $\mathrm{CeSn}_{3}$ phase and the solder matrix leads to the formation of an oxide layer around the $\mathrm{CeSn}_{3}$ phase. The resulting lattice-expansion through both mechanisms of high-temperature storage compresses the solder alloy adjacent to the surrounding oxide layer, causing the formation of hillocks at the edge of the $\mathrm{CeSn}_{3}$ phase in a short period of time.

\section{ACKNOWLEDGMENT}

This work was sponsored by the National Science Council, Taiwan, under Grant No. NSC-94-2216-E002015 .

\section{REFERENCES}

1. L.Y. Jones: Mater. Sci. Technol., 1996, vol. 12, pp. 981-87.

2. L.Y. Wie: Magnesium Alloys and Their Applications, DGM, Oberursel, 1992, pp. 335-42.
3. A.G. Ramirez, H. Mavoori, and S. Jin: Appl. Phys. Lett., 2002, vol. 80, pp. 398-400.

4. Ronald W. Smith: Welding J., 2001, Oct., pp. 30-35.

5. F. Hillen, D. Pickart-Castillo, Ino J. Rass, and E. Lugscheider: Welding and Cutting, 2000, vol. 52, pp. 454-60.

6. X. Ma., Y.F. Qian, and J. Yoshida: J. Alloys Compounds, 2002, vol. 334, pp. 224-27.

7. Z.G. Chen, Y.W. Shi, Z.D. Xia, and Y.F. Yan: J. Electron. Mater., 2002, vol. 31, pp. 1122-28.

8. M.A. Dudek, R.S. Sidhu, and N. Chawla: JOM, 2006, June, pp. 57-62.

9. C.M.L. Wu, D.Q. Yu., C.M.T. Law, and L. Wang: J. Mater. Res., 2002, vol. 17 , pp. $3146-54$.

10. C.M.L. Wu, D.Q. Yu, C.M.T. Law, and L. Wang: J. Electron. Mater., 2002, vol. 31, pp. 928-32.

11. C.M.L. Wu, D.Q. Yu, C.M.T. Law, and L. Wang: J. Electron. Mater., 2002, vol. 31, pp. 921-27.

12. C.M.L. Wu, D.Q. Yu, C.M.T. Law, and L. Wang: Mater. Sci. Eng., 2004, vol. R44, pp. 1-44.

13. T.H. Chuang and S.F. Yen: J. Electron. Mater., vol. 35 (8), pp. $1621-27$.

14. S.H. Liu, Chih Chen, P.C. Liu, and T.J. Chou: J. Appl. Phys., 2004, vol. 95, pp. 7742-47.

15. K.N. Tu: Acta Metall., 1973, vol. 21, pp. 347-54.

16. B.C.H. Steele and J.M. Floyd: Proc. Br. Ceram. Soc., 1971, vol. 19, p. 55. 